\title{
Delayed cyst formation after stereotactic radiosurgery for brain arteriovenous malformations
}

\author{
I. Jonathan Pomeraniec, MD, MBA, ${ }^{1}$ Dale Ding, MD, ${ }^{1}$ Robert M. Starke, MD, MSc, ${ }^{5}$ \\ Kenneth C. Liu, MD, ${ }^{1,3}$ E. Kelly Mrachek, MD, ${ }^{4}$ M. Beatriz Lopes, MD, PhD, ${ }^{4}$ and \\ Jason P. Sheehan, MD, $\mathrm{PhD}^{1,2}$
}

\begin{abstract}
Departments of ${ }^{1}$ Neurosurgery, ${ }^{2}$ Radiation Oncology, ${ }^{3}$ Radiology, and ${ }^{4}$ Neuropathology, University of Virginia Health System, Charlottesville, Virginia; and ${ }^{5}$ Departments of Neurosurgery and Radiology, Jackson Memorial Hospital and University of Miami Hospital, Miami, Florida
\end{abstract}

\begin{abstract}
OBJECTIVE Stereotactic radiosurgery (SRS) is a commonly employed treatment modality for brain arteriovenous malformations (AVMs). However, due to the low frequency of delayed cyst formation after AVM SRS, as well as the prolonged time interval between treatment and its occurrence, the characteristics of post-SRS cyst formation are not well defined. Therefore, the aims of this retrospective cohort study are to determine the rate of cyst formation after SRS for AVMs, identify predictive factors, and evaluate the clinical sequelae of post-SRS cysts.
\end{abstract}

METHODS The authors analyzed an SRS database for AVM patients who underwent SRS at the University of Virginia and identified those who developed post-SRS cysts. Statistical analyses were performed to determine predictors of postSRS cyst formation and the effect of cyst formation on new or worsening seizures after SRS.

RESULTS The study cohort comprised 1159 AVM patients treated with SRS; cyst formation occurred in 17 patients (post-SRS cyst rate of 1.5\%). Compared with patients who did not develop post-SRS cysts, those with cyst formation were treated with a greater number of radiosurgical isocenters (mean $3.8 \mathrm{vs} \mathrm{2.8,} \mathrm{p}=0.047$ ), had a longer follow-up (mean 132 vs 71 months, $p<0.001)$, were more likely to develop radiological radiation-induced changes (RIC) $(64.7 \%$ vs $36.1 \%, p=0.021)$, and had a longer duration of RIC (57 vs 21 months, $p<0.001)$. A higher number of isocenters $(p=$ $0.014)$, radiological RIC ( $p=0.002)$, and longer follow-up $(p=0.034)$ were found to be independent predictors of postSRS cyst formation in the multivariate analysis. There was a trend toward a significant association between cyst formation and new or worsening seizures in univariate analysis $(p=0.054)$.

CONCLUSIONS Patients with greater nidal complexity appear to be more prone to post-SRS cyst formation. The findings of this study emphasize the importance of long-term follow-up for patients who have undergone AVM SRS, even after nidal obliteration is achieved. Post-SRS cysts may be epileptogenic, although seizure outcomes after AVM SRS are multifactorial.

https://thejns.org/doi/abs/10.3171/2017.6.JNS17559

KEY WORDS cyst; Gamma Knife; intracranial arteriovenous malformation; intracranial hemorrhages; stereotactic radiosurgery; stroke; vascular malformations; vascular disorders

$\mathrm{B}$ RAIN arteriovenous malformations (AVMs) are rare, unstable cerebrovascular lesions which, if left untreated, can incite intracranial hemorrhage from nidal rupture, seizures, or focal neurological deficits secondary to chronic vascular steal. $2,11,14,22,42,47$ Stereotactic radiosurgery (SRS) has been widely adopted as an effective treatment for AVMs and represents a minimally invasive, therapeutic alternative to resection, particularly for nidi lo- cated in deep or eloquent brain areas. $1,7,8,12,13,16,23-27,30-32,37,39$, 49,50,52,54,59,61 Both the beneficial and the adverse effects of AVM SRS manifest in a delayed fashion, and each clinical or radiological end point is characterized by its own temporal pattern. ${ }^{26,29,50}$

Cyst formation after AVM SRS is uncommon, occurring in less than $5 \%$ of cases. ${ }^{49}$ Additionally, the time course of cyst development is typically longer than that

ABBREVIATIONS AVM = arteriovenous malformation; RBAS = radiosurgery-based AVM score; RIC = radiation-induced changes; $S R S$ = stereotactic radiosurgery; VRAS = Virginia Radiosurgery AVM Scale.

SUBMITTED March 3, 2017. ACCEPTED June 2, 2017.

INCLUDE WHEN CITING Published online December 1, 2017; DOI: 10.3171/2017.6.JNS17559. 
of more frequently observed adverse events after SRS. ${ }^{45}$ Due to these factors, the characteristics of post-SRS cyst formation in AVM patients treated with SRS are incompletely understood..$^{910,41,50}$ Therefore, the aims of this retrospective cohort study are 1) to determine the rate of cyst formation after SRS for AVMs, 2) to define predictors of post-SRS cyst formation in AVM patients, and 3) to assess the clinical implications of post-SRS cyst formation.

\section{Methods}

\section{Study Design and SRS Technique}

We retrospectively evaluated an institutional database comprising all AVM cases treated with SRS at the University of Virginia from 1989 to 2015. Cases with adequate baseline data and $\geq 12$ months' follow-up after SRS were included for analysis. AVMs treated with volume- or dose-staged SRS were excluded. This study was approved by the University of Virginia institutional review board.

All SRS procedures were performed with the Gamma Knife (Elekta AB). Our institutional Gamma Knife SRS technique for AVM treatment has been previously described. ${ }^{26,54}$ A Leksell $\mathrm{G}$ frame (Elekta AB) was affixed to the patient's calvaria under anesthesia. The angioarchitecture of the AVM nidus was defined with a combination of thin-slice (slide width $\leq 1 \mathrm{~mm}$ ) MRI and digital subtraction angiography. CT was performed for patients in whom MRI was contraindicated. Using Kula (Elekta AB; prior to June 1994) and GammaPlan (Elekta AB; after June 1994) SRS planning software, dose planning was performed by a multidisciplinary team composed of a neurosurgeon, a radiation oncologist, and a medical physicist.

\section{Baseline Data and Variables}

Baseline data were collected from directed chart review and comprised patient, AVM, and SRS variables, as follows. Patient variables were sex and age at the time of SRS. AVM variables were prior hemorrhage, prior embolization, prior resection, size (maximum diameter and volume), location (dichotomized as cortical vs noncortical, and as eloquent vs noneloquent), and venous drainage pattern (dichotomized as single vs multiple draining veins, and as exclusively deep vs component of superficial venous drainage). SRS variables were margin dose, maximum dose, isodose line, and number of isocenters.

Cortical location was defined as the frontal, temporal, parietal, or occipital lobes. Eloquent location was defined, as previously described by Spetzler and Martin, as the following: primary motor, primary somatosensory, language, and primary visual cortices; basal ganglia; thalamus; hypothalamus; internal capsule; brainstem; cerebellar peduncles; and deep cerebellar nuclei. ${ }^{51}$ The Spetzler-Martin grade, Virginia Radiosurgery AVM Scale (VRAS) score, and modified radiosurgery-based AVM score (RBAS) were determined for each patient. ${ }^{51,53,55}$

\section{Follow-Up}

Patients were followed radiologically, with MRI or CT for those unable to undergo MRI, every 6 months for the first 2 years, and then annually thereafter. Cyst formation was defined on neuroimaging as the development of a fluid-filled cavity within or adjacent to the location of the original AVM nidus. Obliteration was defined on MRI as an absence of flow voids and on catheter cerebral angiography as a lack of anomalous arteriovenous shunting. Angiography was performed to confirm obliteration on MRI and to evaluate an AVM remnant for additional intervention(s). Radiation-induced changes (RIC) were defined, on MRI, as T2-weighted hyperintensities in the brain parenchyma adjacent to the nidus. Post-SRS hemorrhage was defined as any neuroimaging evidence of AVMrelated intracranial hemorrhage after the SRS procedure. All neuroimaging studies were assessed by a neurosurgeon and a neuroradiologist at the University of Virginia.

Clinical follow-up was performed concurrently with radiological follow-up, when feasible, and consisted of assessments at the University of Virginia (i.e., inpatient hospital admissions and outpatient clinic appointments) and referring centers or patients' local physicians. Additional imaging was performed for patients who developed new or worsening neurological symptoms. Each patient's neurological function at the most recent follow-up was compared with his or her baseline status prior to SRS. Patients with AVM-associated epilepsy were assessed for worsening of preoperative seizure status, whereas those without AVM-associated epilepsy were assessed for de novo seizures after SRS.

\section{Statistical Analysis}

Continuous variables were presented as mean and standard deviation, and categorical variables were presented as frequency. Continuous variables were compared using Student t-tests, both with and without equal variance (Levene test), as necessary. Categorical variables were compared using Pearson's chi-square test or Fisher's exact test, as appropriate. The aforementioned patient, AVM, and SRS variables, along with obliteration, RIC, post-SRS hemorrhage, and follow-up duration, were assessed in univariate logistic regression analysis to identify factors associated with post-SRS cyst formation. To determine the clinical implications of cyst formation, the baseline variables and post-SRS outcome measures listed above, along with the presence of cyst formation, were assessed in univariate logistic regression analysis to identify factors associated with post-SRS cyst formation. Additionally, patient and AVM characteristics were assessed in univariate and multivariate analysis to determine the role of post-SRS cyst formation on new or worsening seizures. Factors with $p<0.20$ in each of the univariate analyses were entered into a multivariate logistic regression analysis to determine independent predictors of the respective radiological or clinical end point. ${ }^{3}$ For the purposes of this study, a $\mathrm{p}$ value $<0.05$ was considered statistically significant. ${ }^{3}$

\section{Results \\ Cyst Formation After SRS for AVMs}

Of the 1159 AVM patients who underwent SRS and were eligible for inclusion in the study cohort, post-SRS cyst formation occurred in 17 (1.5\%). Patients with postSRS cyst formation were predominately female $(70.6 \%)$. 
TABLE 1. Comparison of patient, nidal, and SRS characteristics between AVM patients with and without cyst formation

\begin{tabular}{lccc}
\hline \multicolumn{1}{c}{ Factor } & $\begin{array}{c}\text { Post-SRS } \\
\text { Cyst }(\mathrm{n}=17)\end{array}$ & $\begin{array}{c}\text { No Post-SRS } \\
\text { Cyst }(\mathrm{n}=1142)\end{array}$ & $\begin{array}{c}\mathrm{p} \\
\text { Value }\end{array}$ \\
\hline Male sex & $5(29.4)$ & $600(52.5)$ & 0.085 \\
\hline Age in yrs (mean) & $27.0 \pm 15.6$ & $33.4 \pm 16.0$ & 0.102 \\
\hline Prior AVM hemorrhage & $7(41.2)$ & $629(55.1)$ & 0.327 \\
\hline Prior AVM embolization & $6(35.3)$ & $270(23.6)$ & 0.259 \\
\hline Prior AVM resection & $2(11.8)$ & $125(10.9)$ & 0.709 \\
\hline Diameter in cm (mean) & $2.6 \pm 1.3$ & $2.3 \pm 0.9$ & 0.176 \\
\hline Volume in cm ${ }^{3}$ (mean) & $3.9 \pm 3.1$ & $3.5 \pm 3.3$ & 0.620 \\
\hline Cortical location & $6(35.3)$ & $386(33.8)$ & 1.000 \\
\hline Eloquent location & $11(64.7)$ & $755(66.1)$ & 1.000 \\
\hline Single draining vein & $9(52.9)$ & $637(55.8)$ & 0.811 \\
\hline Deep venous drainage & $8(47.1)$ & $620(54.3)$ & 0.63 \\
\hline SM grade (mean) & $2.5 \pm 1.0$ & $2.4 \pm 0.9$ & 0.650 \\
\hline VRAS score (mean) & $2.1 \pm 0.8$ & $2.1 \pm 1.0$ & 1.000 \\
\hline RBAS (mean) & $1.23 \pm 0.45$ & $1.33 \pm 0.46$ & 0.374 \\
\hline Margin dose in Gy (mean) & $21.7 \pm 3.6$ & $21.2 \pm 3.4$ & 0.544 \\
\hline Maximum dose in Gy (mean) & $37.4 \pm 8.1$ & $39.5 \pm 7.2$ & 0.235 \\
\hline Isodose line, \% (mean) & $59.6 \pm 13.1$ & $54.8 \pm 11.0$ & 0.074 \\
\hline No. of isocenters (mean) & $3.8 \pm 4.6$ & $2.8 \pm 2.0$ & 0.047 \\
\hline Duration of follow-up in mos & $131.9 \pm 50.3$ & $71.3 \pm 55.0$ & $<0.001$ \\
\hline (mean) & & & \\
\hline
\end{tabular}

SM = Spetzler-Martin.

Values are number of cases (\%) unless otherwise indicated. Mean values are presented \pm SD. Boldface type indicates statistical significance $(p<0.05)$.

* Spetzler-Martin grades were converted to Arabic numerals for purposes of statistical analysis.

At the time of SRS, the mean age of the patients who subsequently developed cysts was 27.0 years. In this group of 17 patients, 7 had AVMs that were previously ruptured (41.2\%). Prior AVM interventions included embolization in 6 patients (35.3\%) and resection in 2 (11.8\%). The mean nidus diameter and size were $2.6 \mathrm{~cm}$ and 3.9 $\mathrm{cm}^{3}$, respectively. The Spetzler-Martin grade was I in 3 patients (17.6\%), II in 6 (35.3\%), III in $5(29.4 \%)$, and IV in 3 patients $(17.6 \%)$. The VRAS score was 1 in 5 patients (29.4\%), 2 in 6 patients (35.3\%), and 3 in 6 patients (35.3\%). The mean radiosurgical margin dose was 21.7 Gy, and the mean number of isocenters was 3.8.

After a mean follow-up of 131.9 months, AVM obliteration was achieved in 10 cases $(58.8 \%)$. RIC were radiologically evident in 11 patients $(64.7 \%)$, symptomatic in 3 $(17.6 \%)$, and permanent in 1 (5.9\%). The mean intervals between SRS and the onset of RIC and duration of RIC were 11.9 and 56.5 months, respectively. Post-SRS hemorrhage occurred in 3 patients (17.6\%). The mean interval between SRS and cyst formation was $90.1 \pm 42.4$ months (range 21.1-154.5 months).

\section{Comparison of AVM Patients With Versus Without Post-SRS Cyst Formation}

Table 1 compares the patient, nidal, and SRS characteristics between AVM patients with and without cyst forma-
TABLE 2. Comparison of outcomes after SRS between AVM patients with and without cyst formation

\begin{tabular}{lccc}
\hline \multicolumn{1}{c}{ Factor } & $\begin{array}{c}\text { Post-SRS } \\
\text { Cyst }(\mathrm{n}=17)\end{array}$ & $\begin{array}{c}\text { No Post-SRS } \\
\text { Cyst }(\mathrm{n}=1142)\end{array}$ & $\begin{array}{c}\mathrm{p} \\
\text { Value }\end{array}$ \\
\hline AVM obliteration & $10(58.8)$ & $691(60.5)$ & 1.000 \\
\hline Radiological RIC & $11(64.7)$ & $412(36.1)$ & $\mathbf{0 . 0 2 1}$ \\
\hline Symptomatic RIC & $3(17.6)$ & $380(33.3)$ & 0.204 \\
\hline Permanent RIC & $1(5.9)$ & $23(2.0)$ & 0.301 \\
\hline $\begin{array}{l}\text { Interval btwn radiosurgery } \\
\text { \& RIC in mos (mean) }\end{array}$ & $11.9 \pm 6.4$ & $12.4 \pm 11.4$ & 0.857 \\
\hline $\begin{array}{l}\text { Duration of RIC in mos } \\
\text { (mean) }\end{array}$ & $56.5 \pm 35.0$ & $21.0 \pm 17.7$ & $<0.001$ \\
\hline Post-SRS hemorrhage & $3(17.6)$ & $96(8.4)$ & 0.172 \\
\hline
\end{tabular}

Values are number of cases (\%) unless otherwise indicated. Mean values are presented \pm SD. Boldface type indicates statistical significance $(p<0.05)$.

tion. Patients who developed post-SRS cysts were treated with a significantly greater number of radiosurgical isocenters (mean 3.8 vs $2.8, \mathrm{p}=0.047$ ) and had significantly longer duration of follow-up (131.9 vs 71.3 months, $\mathrm{p}<$ 0.001). In the post-SRS cyst subgroup, there was a trend toward a higher frequency of patients with female sex (70.6\% vs $47.5 \%, p=0.085$ ) and younger age (mean 27.0 vs 33.4 years, $p=0.102$ ), and lower maximum SRS dose to the AVM (37.4 vs $39.5 \mathrm{~Gy}, \mathrm{p}=0.235)$.

Table 2 compares the outcomes after SRS between AVM patients with and without cyst formation. Patients who developed post-SRS cysts were significantly more likely to have radiological RIC $(64.7 \%$ vs $36.1 \%$, p = $0.021)$, although the rates of symptomatic $(\mathrm{p}=0.204)$ and permanent $(\mathrm{p}=0.301)$ RIC did not differ significantly between those who did and did not have cysts. The duration of RIC was significantly longer in the post-SRS cyst subgroup (56.5 vs 21.0 months, $\mathrm{p}<0.001)$. The mean interval between SRS and cyst formation was $90.1 \pm 42.4$ months.

\section{Predictors and Clinical Implications of Post-SRS Cyst Formation}

Table 3 details the results of univariate and multivariate logistic regression analyses for predictors of post-SRS cyst formation. In the multivariate analysis, a higher number of radiosurgical isocenters $(p=0.014)$, the presence of radiologically evident RIC ( $p=0.002)$, and longer follow-up duration $(\mathrm{p}=0.034)$ were found to be independent predictors of post-SRS cyst formation. The presence of radiological RIC was the strongest independent predictor of cyst formation (OR 7.55), followed by a greater number of isocenters (OR 1.20).

Table 4 details the results of univariate and multivariate logistic regression analyses for predictors of new or worsening seizures after SRS. In the multivariate analysis, a lack of prior AVM hemorrhage ( $<<0.001)$, larger AVM maximum diameter $(\mathrm{p}<0.001)$, and exclusively superficial venous drainage $(\mathrm{p}=0.001)$ were found to be independent predictors of new or worsening seizures. The association between post-SRS cyst formation and new or worsening seizures status trended toward significance in the univariate analysis (OR 3.0, 95\% CI 0.98-8.86, $\mathrm{p}=0.054)$. How- 
TABLE 3. Univariate and multivariate logistic regression analyses for predictors of cyst formation after AVM SRS

\begin{tabular}{|c|c|c|c|c|c|c|}
\hline \multirow[b]{2}{*}{ Factor } & \multicolumn{3}{|c|}{ Univariate } & \multicolumn{3}{|c|}{ Multivariate } \\
\hline & OR & $95 \% \mathrm{Cl}$ & $p$ Value & OR & $95 \% \mathrm{Cl}$ & $\mathrm{p}$ Value \\
\hline Female sex & 2.54 & $0.89-7.27$ & 0.082 & - & - & NS \\
\hline Superficial AVM location & 1.16 & $0.93-1.43$ & 0.183 & - & - & NS \\
\hline Larger AVM max diameter & 2.66 & $1.00-7.08$ & 0.050 & - & - & NS \\
\hline Higher no. of isocenters & 1.14 & $0.99-1.30$ & 0.061 & 1.20 & $1.04-1.38$ & 0.014 \\
\hline Radiological RIC & 7.70 & $2.20-26.97$ & $0.001^{*}$ & 7.55 & $2.13-26.80$ & 0.002 \\
\hline Longer follow-up duration & 1.01 & $1.00-1.02$ & $0.021^{*}$ & 1.01 & $1.00-1.02$ & 0.034 \\
\hline
\end{tabular}

NS $=$ not statistically significant (in the multivariate analysis, $p \geq 0.05$ ).

Only factors with $p<0.20$ in the univariate analysis are listed. Boldface type indicates statistical significance in the multivariate analysis.

* Statistically significant in the univariate analysis $(p<0.05)$.

ever, cyst formation was not significant in the multivariate analysis $(\mathrm{p}=0.495)$.

\section{Management and Outcomes of Post-SRS Cyst Patients}

Patients who developed cysts presented with 1 or more of the following symptoms: headache $(\mathrm{n}=5,29.4 \%)$, sensorimotor disturbance $(\mathrm{n}=5,29.4 \%)$, seizure $(\mathrm{n}=5$, $29.4 \%)$, visual deficit $(n=4,23.5 \%)$, speech disturbance $(\mathrm{n}=4,23.5 \%)$, nausea/vomiting $(\mathrm{n}=1,5.9 \%)$, and cognitive/memory $(\mathrm{n}=1,5.9 \%)$. The presenting symptoms of 2 patients (11.8\%) were unknown.

The management strategies and outcomes for patients who developed post-SRS cysts are summarized in Fig. 1. Of 17 post-SRS cyst patients, 4 (23.5\%) underwent surgical intervention; in the remaining 13 cases $(76.5 \%)$, the cysts were managed conservatively. Initially, 3 patients (17.6\%) underwent craniotomy for cyst fenestration and/or resection. One patient's cyst was initially treated with an Ommaya reservoir (5.9\%), but the patient subsequently underwent cystoperitoneal shunt placement and eventually craniotomy for cyst fenestration (Fig. 2). At last followup, the neurological condition was improved in 9 patients $(52.9 \%)$, was unchanged in $5(29.4 \%)$, and had deteriorated in $3(17.6 \%)$, including 1 patient who died of unrelated sequelae of congestive heart failure.

\section{Discussion}

Delayed cyst formation is an uncommon complication following SRS for AVMs, occurring with a frequency of less than $5 \% .{ }^{15,18,45}$ The latency period between SRS and cyst development is typically greater than that for other more frequently observed adverse events, such as RIC and post-SRS hemorrhage. ${ }^{17-19,21,29,44,45,60}$ Although the etiology of cyst formation and time course of enlargement

TABLE 4. Univariate and multivariate logistic regression analyses for predictors of new or worsening seizures after AVM SRS

\begin{tabular}{|c|c|c|c|c|c|c|}
\hline \multirow[b]{2}{*}{ Variable } & \multicolumn{3}{|c|}{ Univariate } & \multicolumn{3}{|c|}{ Multivariate } \\
\hline & OR & $95 \% \mathrm{Cl}$ & $p$ Value & $\mathrm{OR}$ & $95 \% \mathrm{Cl}$ & $p$ Value \\
\hline Post-SRS cyst formation & 2.95 & $0.98-8.86$ & 0.054 & - & - & NS \\
\hline Older age & 1.01 & $1.00-1.02$ & 0.153 & - & - & NS \\
\hline No prior AVM hemorrhage & 22.95 & $14.29-36.87$ & $<0.001^{*}$ & 17.87 & $11.02-28.95$ & $<0.001$ \\
\hline No prior AVM resection & 2.49 & $1.40-4.43$ & $0.002^{*}$ & - & - & NS \\
\hline Prior AVM embolization & 1.65 & $1.19-2.28$ & $0.003^{*}$ & - & - & NS \\
\hline Larger AVM max diameter & 1.76 & $1.50-2.08$ & $<0.001^{*}$ & 1.53 & $1.25-1.88$ & $<0.001$ \\
\hline Larger AVM volume & 1.15 & $1.09-1.20$ & $<0.001^{*}$ & - & - & NS \\
\hline Exclusively superficial venous drainage & 2.99 & $2.19-4.08$ & $<0.001^{*}$ & 1.82 & $1.26-2.62$ & 0.001 \\
\hline Lower SM grade & 1.23 & $1.03-1.46$ & $0.021^{*}$ & $-\dagger$ & $-\dagger$ & $-\dagger$ \\
\hline Lower VRAS score & 2.17 & $1.88-2.51$ & $<0.001^{*}$ & $-\dagger$ & $-\dagger$ & $-\dagger$ \\
\hline Higher RBAS & 1.57 & $1.16-2.15$ & $0.004^{*}$ & $-\dagger$ & $-\dagger$ & $-\dagger$ \\
\hline Lower margin dose & 1.10 & $1.05-1.15$ & $<0.001^{*}$ & - & - & NS \\
\hline Higher no. of isocenters & 1.10 & $1.03-1.18$ & $0.003^{*}$ & - & - & NS \\
\hline No AVM obliteration after SRS & 2.08 & $1.53-2.81$ & $<0.001^{*}$ & - & - & NS \\
\hline Radiological RIC & 1.90 & $1.41-2.55$ & $<0.001^{*}$ & - & - & NS \\
\hline
\end{tabular}

Only factors with $p<0.20$ in the univariate analysis are listed. Boldface type indicates statistical significance in the multivariate analysis.

* Statistically significant in the univariate analysis $(p<0.05)$.

$\dagger$ Grading scales were not included in the multivariate analysis. 


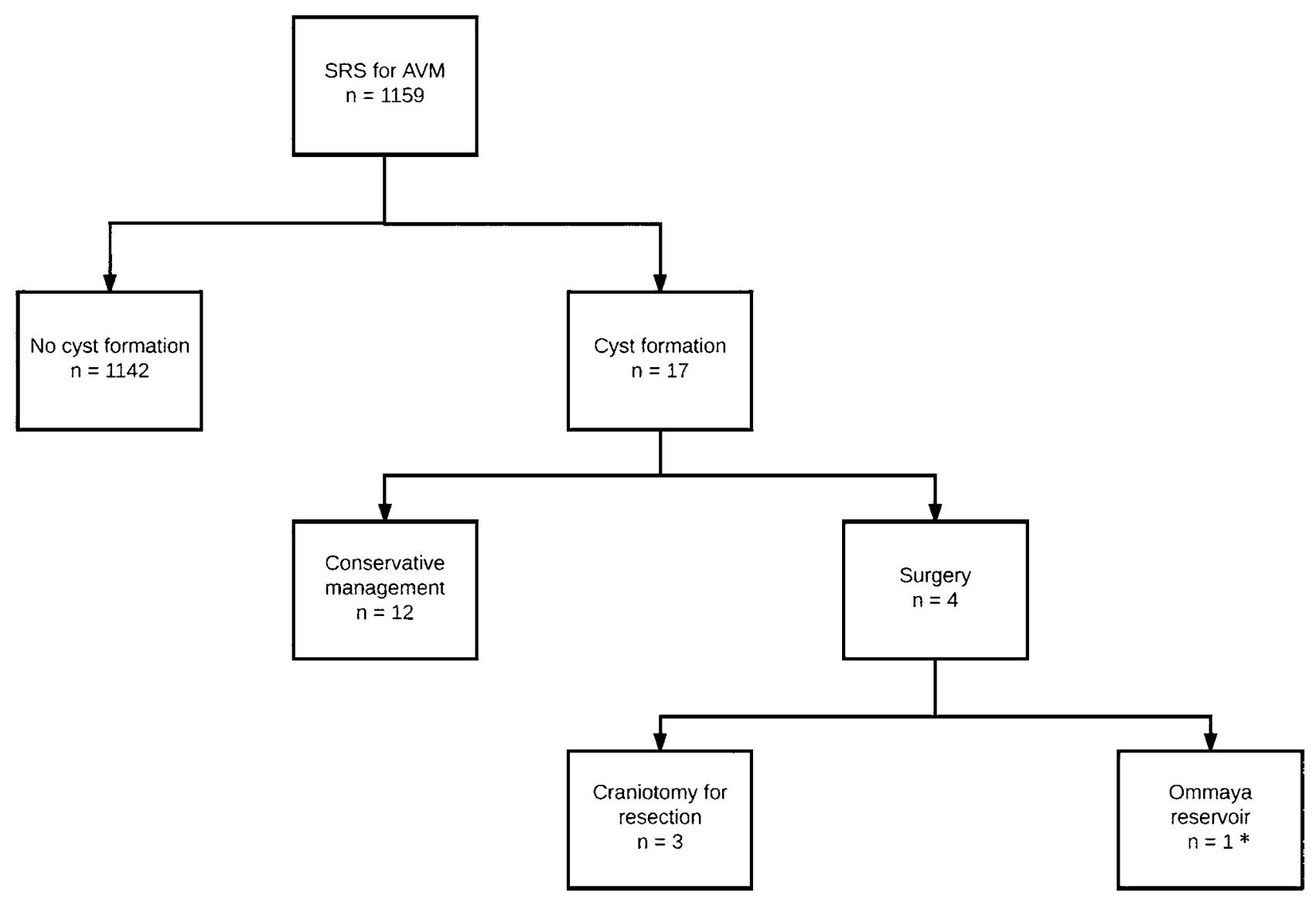

FIG. 1. Flow diagram showing management of post-SRS cysts. *One patient underwent initial placement of an Ommaya reservoir, which was subsequently converted to a cystoperitoneal shunt, and then eventually underwent craniotomy for resection cyst fenestration. This patient is not included in the craniotomy group in this figure. Overall, 4 patients underwent craniotomy for cyst fenestration and/or resection.

remain unclear, cysts can become symptomatic secondary to mass effect, which can ultimately necessitate surgical intervention..$^{48-50}$ Due to the low frequency of cyst formation, combined with the long follow-up duration necessary to detect this complication, relatively little is known about post-SRS cysts in AVM patients.

Prior studies indicate that the diagnosis of cyst formation seems to increase concurrently with follow-up duration. Pan et al ${ }^{45}$ highlighted the importance of long-term surveillance, reporting that their overall cyst formation rate of $1.6 \%$ increased to $3.6 \%$ when only data from patients with at least 5 years of follow-up were analyzed. Cyst formation has also been associated with AVM angioarchitectural and SRS treatment characteristics. ${ }^{26,34} \mathrm{Pan}$ et al. ${ }^{45}$ found prior AVM embolization and RIC to be associated with cyst formation. In an analysis of 444 unruptured AVMs treated with SRS at our center, we similarly found a significant relationship between RIC and cyst development. ${ }^{20}$ Izawa et al. ${ }^{34}$ identified higher SRS maximum dose, larger AVM volume, lobar nidus location, and AVM obliteration as significant predictors of cyst formation.

In the current study, the incidence of delayed cyst formation was $1.5 \%$. Radiological RIC was the strongest independent predictor of cyst formation (OR 7.55, $\mathrm{p}=$ 0.002 ), and the duration of RIC was significantly greater in patients who developed cysts than in those who did not develop cysts $(p<0.001)$. Since the onset of RIC generally precedes that of cyst formation by years, it is possible that RIC may increase the susceptibility of perinidal brain parenchyma to the development of post-SRS cysts. However, the pathobiological and mechanistic relationships between RIC and cyst formation have not been thoroughly explored. A larger number of isocenters (which can act as a relevant surrogate for many treatment variables, such as volume, 3D complexity of the target volume, conformality, and gradient index) was also an independent predictor of cyst formation $(p=0.014)$, which suggests that AVMs with greater morphological complexity may be more prone to cyst development.

The final independent predictor of cyst formation was longer follow-up duration ( $\mathrm{p}=0.034)$, which is consistent with the positive correlation between cyst detection and follow-up found in previous reports. ${ }^{17-19,21,29,44,60}$ Additionally, 59\% of patients who developed post-SRS cysts had obliterated AVMs. Taken together, these findings support the necessity of long-term follow-up after SRS for AVMs, even after nidal obliteration has been achieved (Fig. 3). Furthermore, the incidence of post-SRS cyst formation is likely underestimated in the literature, as well as in the present study. Only $35 \%$ of patients who did not develop 

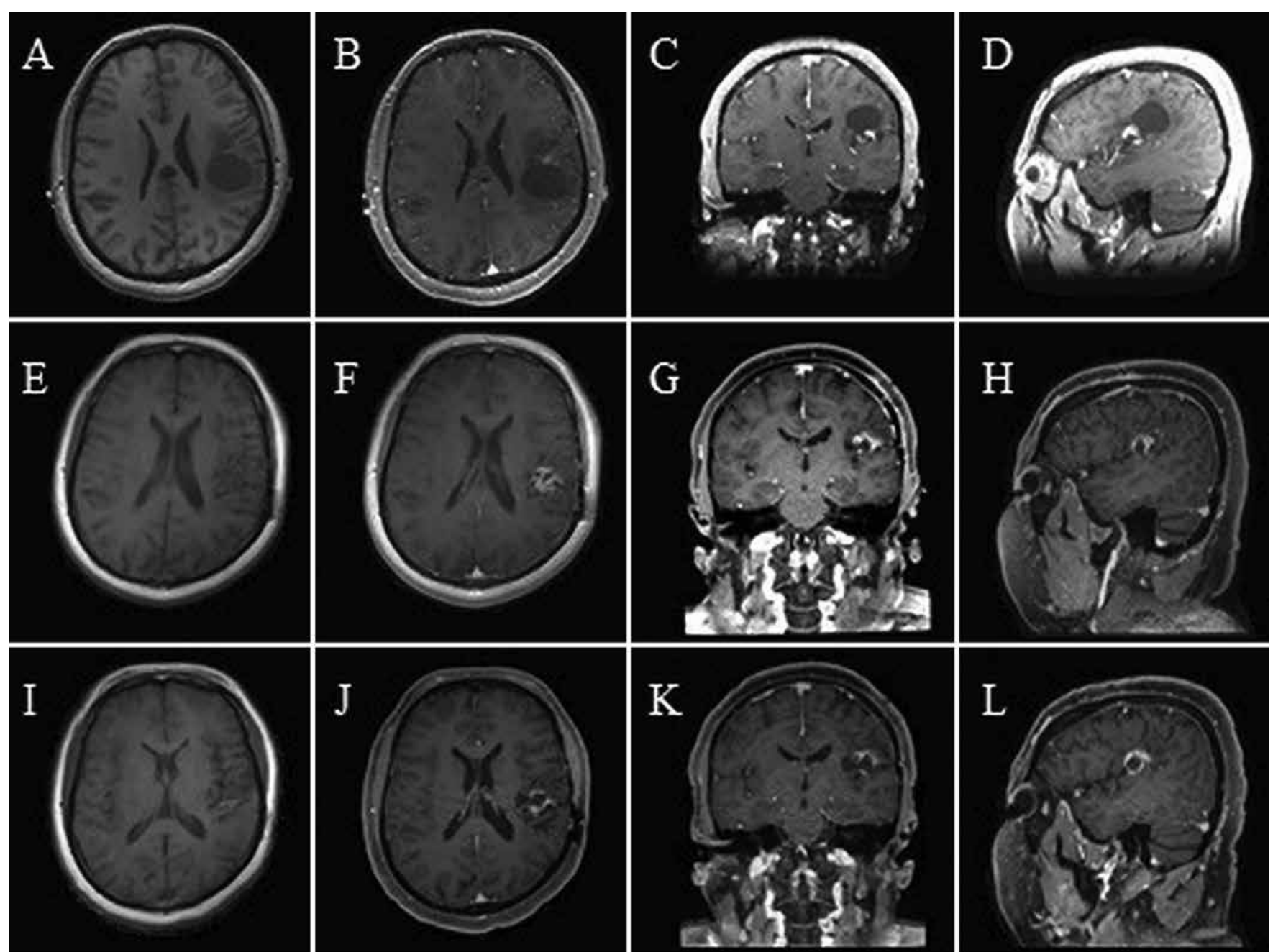

FIG. 2. Case example. This 39-year-old woman with a history of seizures related to a left posterior frontal AVM subsequently underwent surgical management of a left periodontal cyst that formed following radiosurgery. The cyst was discovered 61 months following radiosurgery and exhibited progressive enlargement over serial MRI. The patient underwent stereotactic placement of the left frontal Ommaya reservoir for cyst aspiration 106 months post-SRS with subsequent reservoir removal and placement of a cystoperitoneal shunt 10 months later. Two months later, the patient underwent shunt removal and left frontotemporal craniotomy and fenestration of the cyst with awake language monitoring. A-D: Pre- and postcontrast T1-weighted MR images obtained before Ommaya reservoir placement. E-H: Pre-and postcontrast T1-weighted MR images obtained immediately following surgery. I-L: Pre- and postcontrast T1-weighted MR images obtained at last follow-up (138 months post-SRS).

cysts in our study cohort had follow-up longer than the mean interval to cyst development of 90 months. Closer monitoring for seizures may be prudent in patients with post-SRS cysts, given that the relationship between postSRS cyst formation and new or worsening seizures trended toward significance $(\mathrm{p}=0.054)$. However, given the low incidence of worsening seizure status or de novo seizures after AVM SRS, prophylactic administration of anticonvulsants in post-SRS cyst patients does not appear warranted. ${ }^{6,11}$

\section{Proposed Mechanisms of Post-SRS Cyst Formation}

The pathophysiology and long-term mechanism of cyst formation following SRS remains relatively obscure. Several theoretical overtures hold that nidal vessel injury leads to angiomatous changes, increased vessel permeability, and breakdown of the blood-brain barrier (Fig. 4). Shuto and colleagues ${ }^{49,50}$ postulated that radiation to the nidus can lead to inflammation with subsequent fluid extravasation, inflammatory infiltrate, granulomatous metamorphoses, and eventually chronic hemorrhage from nascent capillary vessels. These changes could culminate in fragile vessels that enlarge and bleed repeatedly within cystic cavities. Increased protein and osmotic pressure would cause the cyst to enlarge, hemorrhage, and continue in cyclical fashion. Hemorrhage into brain parenchyma causes enlarging cysts, whereas hemorrhage into angiomatous lesions causes chronic encapsulated expanding hematomas.

Pan et al. suggested that delayed cyst formation follows a disparate pathophysiological course compared with that of post-SRS hemorrhage. ${ }^{4,12,34,45,57,58}$ Delayed radiation effects were observed with both chronic encapsulated expanding hematoma and nodular lesion. ${ }^{50}$ Microscopically, 

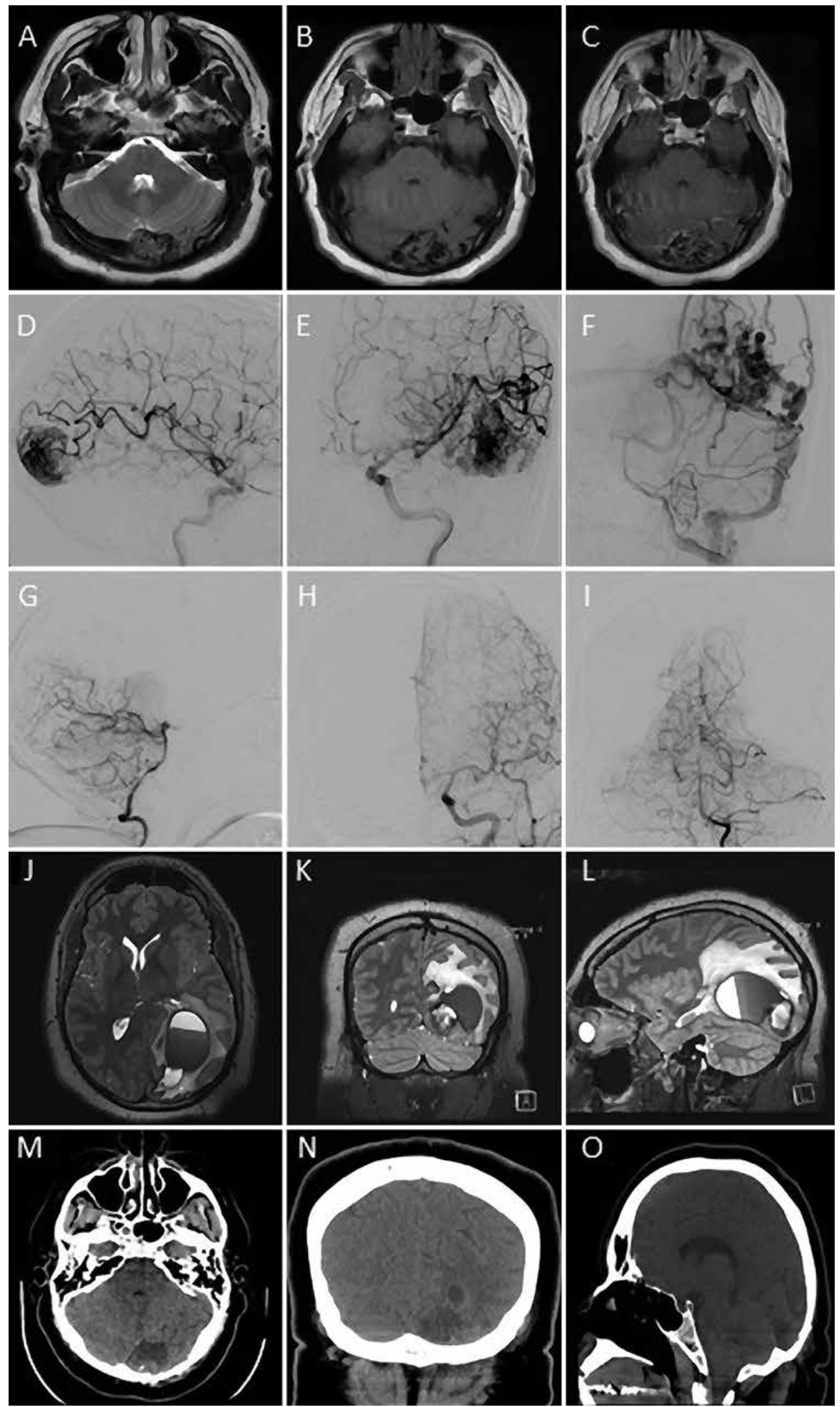

FIG. 3. Case example. This 33-year-old man presented with worsening headaches and blurry vision. Brain MRI at presentation (A-C) showed a left occipital AVM abutting the dura posteriorly and tentorium inferiorly. Cerebral angiography performed at the time $(\mathbf{D}-\mathrm{F})$ showed a $2.7 \times 1.7 \times 2.6 \mathrm{~cm}$ lesion fed primarily by temporoparietal and occipital branches of the left posterior cerebral artery, as well as enlarged temporal occipital and angular branches from the left middle cerebral artery and a tiny left posterior meningeal branch from the left vertebral artery. The patient underwent Gamma Knife SRS 1 month later. FIG. 3. (continued) $\rightarrow$ 
FIG. 3. Approximately 3.5 years after treatment, the patient's symptoms returned and were managed conservatively. Repeat angiography (G-I) showed no evidence of residual AVM (e.g., successful outcome from SRS procedure). Approximately 5 years after Gamma Knife radiosurgery, MRI $(\mathrm{J}-\mathrm{L})$ revealed a new hemorrhage into the cystic cavity, measuring $7 \times 4 \times 4 \mathrm{~cm}$ with associated edema, herniation, and $5 \mathrm{~mm}$ of midline shift. The patient subsequently underwent left occipital craniotomy for resection of a vascular radiation-induced malformation and drainage of the associated cyst. He ultimately recovered well with improved edema and mass effect on brain CT (M-0) 1 month after surgery. A-C: Axial T2-weighted (A), T1-weighted precontrast (B), and T1weighted postcontrast (C) MR images obtained at presentation. D-F: Left internal carotid artery (ICA) injection lateral view (D and E) and left vertebral artery $(V A)$ injection anteroposterior $(A P)$ view $(F)$ cerebral angiograms obtained at presentation. G-I: Left ICA injection lateral view (G and $\mathrm{H}$ ) and left VA injection AP view $(\mathrm{I})$ cerebral angiograms obtained approximately 3.5 years after treatment. J-L: Axial (J), coronal (K), and sagittal (L) T2-weighted MR images. M-O: Axial (M), coronal (N), and sagittal (O) CT images obtained 1 month after surgery without administration of a contrast agent.

these lesions revealed damage to dilated capillary walls with protein exudate, hyalinization and fibrinoid necrosis, and microhemorrhage..$^{50}$ In this way, prior AVM hemorrhage and embolization may in fact increase tissue vulnerability and encourage cyst formation., ${ }^{5,43}$

\section{Management of Post-SRS Cysts}

The timing and spectrum of delayed cyst development remains imprecise and, as a consequence, optimal management strategies remain fragmented. At most centers, including our own, patients can be followed initially with surveillance imaging. Intervention is typically reserved for patients with symptomatic and/or enlarging cysts, particularly those encroaching on eloquent brain areas. ${ }^{28,40,50,56}$ Still, prior series suggest that some patients with growing cysts can remain relatively free of symptoms and that some cysts even spontaneously decrease in size. ${ }^{49}$

Several therapeutic options are effective for cyst management. Placement of an Ommaya reservoir with cyst aspiration can offer immediate symptomatic relief; repeated aspiration can help to control cyst growth. ${ }^{36,48,49}$ Cystoperitoneal shunting can provide a remedy for cysts with simple anatomy and patients with high surgical comorbidity. ${ }^{35,46}$ Craniotomy for cyst fenestration and/or resection is more invasive but offers the prospect of cure for patients with cysts with local mass effect that persists despite shunting, as well as those with intracystic septations. ${ }^{33,46}$ Patients with cysts and persistently filling AVMs after SRS can

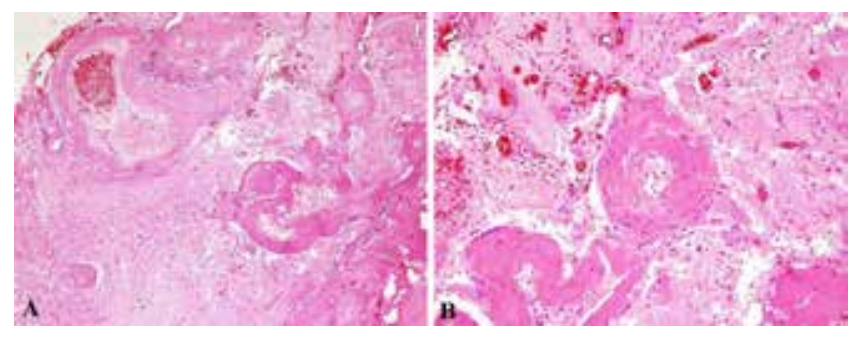

FIG. 4. Radiation-induced vascular malformation of the left occipital lobe with clinically associated post-SRS cyst in a 38-year-old man (same case as in Fig. 3, approximately 5 years after presentation). A: Section of the resected malformation showing tortuous and disorganized vascular channels of varying diameter and wall thickness, including arterialization of dilated venous structures, with some of the vessels containing fibrin thrombus. There is intervening entrapped gliotic brain parenchyma containing reactive astrocytes, hemosiderin deposition, and hemosiderin-laden macrophages. B: Section of the resected malformation showing vascular structures with thickened vessel walls and hyalinization of vessel walls with degenerative features. $H \& E$, original magnification $\times 40(A)$ and $\times 100(B)$. Figure is available in color online only. undergo simultaneous cyst treatment and extirpation of residual nidi. Resection of radiation-induced vascular malformations may facilitate resolution of the cysts, although the benefit of this approach has not been verified. ${ }^{38}$

\section{Study Limitations}

The present comparison of AVM patients with delayed cyst formation after SRS has several weaknesses that should be noted. This is a single-center retrospective analysis that is subject to the selection, treatment, and referral biases of our institution and physicians. Some of these biases may be ameliorated by future studies of post-SRS cysts in multicenter cohorts. Due to the longitudinal nature of the follow-up, detailed clinical outcome data were not available for some patients in this study. Therefore, we are unable to compare the neurological and functional outcomes of patients who developed post-SRS cysts to those without cysts.

Because the mean follow-up duration of patients with post-SRS cysts was significantly longer than that of patients without cysts (132 vs 71 months, respectively; $\mathrm{p}<$ 0.001 ), the incidence of cyst formation may be underestimated in this study. Therefore, further prospective studies with long-term follow-up are necessary to better characterize the incidence, timing, and natural history of post-SRS cysts in AVM patients, as well as the temporal relationship between cyst formation and other radiological end points (i.e., obliteration, post-SRS hemorrhage, RIC). Of note, the International Gamma Knife Research Foundation (IG$\mathrm{KRF}$ ) is currently embarking on a multicenter study of delayed cyst formation in this patient cohort. Our study is also unable to characterize the optimal treatment modality for post-SRS cysts, since $75 \%$ of initial cyst interventions were craniotomies, and the only patient to undergo a less invasive procedure (Ommaya reservoir implantation) also eventually underwent a craniotomy.

\section{Conclusions}

AVM patients who undergo SRS with treatment plans that use a greater number of isocenters harbor a greater risk of developing cysts, which suggests a relationship between increasing nidal complexity and post-SRS cyst formation. Long-term follow-up is necessary to screen AVM patients for cyst formation after SRS, even after obliteration of the nidus. Patients who develop cysts after AVM SRS may be more susceptible to new or worsening seizures, although factors other than cyst formation appear to exert a greater influence on seizure outcomes. Thus, prophylactic use of anticonvulsants in AVM patients with 
cysts does not appear warranted. Surgical intervention should be considered for enlarging or symptomatic cysts. However, the optimal management algorithm for post-SRS cysts has not been defined. Further studies are warranted to elucidate the potential relationship of RIC to the pathogenesis of post-SRS cysts in AVM patients.

\section{References}

1. Al Hinai Q, Tampieri D, Souhami L, Sadikot A, Sinclair D, Leblanc R: Cyst formation following radiosurgery for AVMs: report of 3 cases. Can J Neurol Sci 38:734-740, 2011

2. Al-Shahi R, Warlow C: A systematic review of the frequency and prognosis of arteriovenous malformations of the brain in adults. Brain 124:1900-1926, 2001

3. Altman DG: Practical Statistics for Medical Research. Boca Raton: Chapman \& Hall/CRC, 1999

4. Arslan I, Tezcanli E, Yilmaz M, Cizmeli O, Sengoz M, Peker S: Gamma Knife radiosurgery for arteriovenous malformations: clinical series of 199 patients. Turk Neurosurg 27:301-308, 2017

5. Buell TJ, Ding D, Starke RM, Webster Crowley R, Liu KC: Embolization-induced angiogenesis in cerebral arteriovenous malformations. J Clin Neurosci 21:1866-1871, 2014

6. Chen CJ, Chivukula S, Ding D, Starke RM, Lee CC, Yen CP, et al: Seizure outcomes following radiosurgery for cerebral arteriovenous malformations. Neurosurg Focus 37(3):E17, 2014

7. Cohen-Inbar O, Ding D, Chen CJ, Sheehan JP: Stereotactic radiosurgery for deep intracranial arteriovenous malformations, part 1: Brainstem arteriovenous malformations. J Clin Neurosci 24:30-36, 2016

8. Cohen-Inbar O, Ding D, Sheehan JP: Stereotactic radiosurgery for deep intracranial arteriovenous malformations, part 2: Basal ganglia and thalamus arteriovenous malformations. J Clin Neurosci 24:37-42, 2016

9. Ding D: Mechanisms of cyst formation after radiosurgery for intracranial arteriovenous malformations. Clin Neurol Neurosurg 124:192-193, 2014

10. Ding D: Pathogenesis of radiosurgery-induced cyst formation in patients with cerebral arteriovenous malformations. Acta Neurochir (Wien) 157:775-777, 2015

11. Ding D, Quigg M, Starke RM, Xu Z, Yen CP, Przybylowski CJ, et al: Radiosurgery for temporal lobe arteriovenous malformations: effect of temporal location on seizure outcomes. J Neurosurg 123:924-934, 2015

12. Ding D, Starke RM, Kano H, Lee JY, Mathieu D, Pierce J, et al: Stereotactic radiosurgery for Spetzler-Martin Grade III arteriovenous malformations: an international multicenter study. J Neurosurg 126:859-871, 2017

13. Ding D, Starke RM, Kano H, Mathieu D, Huang P, Kondziolka D, et al: Radiosurgery for cerebral arteriovenous malformations in A Randomized Trial of Unruptured Brain Arteriovenous Malformations (ARUBA)-eligible patients: a multicenter study. Stroke 47:342-349, 2016

14. Ding D, Starke RM, Quigg M, Yen CP, Przybylowski CJ, Dodson BK, et al: Cerebral arteriovenous malformations and epilepsy, part 1: predictors of seizure presentation. World Neurosurg 84:645-652, 2015

15. Ding D, Starke RM, Yen CP, Sheehan JP: Radiosurgery for cerebellar arteriovenous malformations: does infratentorial location affect outcome? World Neurosurg 82:e209-e217, 2014

16. Ding D, Xu Z, Shih HH, Starke RM, Yen CP, Cohen-Inbar O, et al: Worse outcomes after repeat vs initial stereotactic radiosurgery for cerebral arteriovenous malformations: a retrospective matched-cohort study. Neurosurgery 79:690-700, 2016
17. Ding D, Xu Z, Shih HH, Starke RM, Yen CP, Sheehan JP: Stereotactic radiosurgery for partially resected cerebral arteriovenous malformations. World Neurosurg 85:263-272, 2016

18. Ding D, Xu Z, Starke RM, Yen CP, Shih HH, Buell TJ, et al: Radiosurgery for cerebral arteriovenous malformations with associated arterial aneurysms. World Neurosurg 87:77-90, 2016

19. Ding D, Xu Z, Yen CP, Starke RM, Sheehan JP: Radiosurgery for cerebral arteriovenous malformations in elderly patients: effect of advanced age on outcomes after intervention. World Neurosurg 84:795-804, 2015

20. Ding D, Xu Z, Yen CP, Starke RM, Sheehan JP: Radiosurgery for unruptured cerebral arteriovenous malformations in pediatric patients. Acta Neurochir (Wien) 157:281-291, 2015

21. Ding D, Yen CP, Starke RM, Xu Z, Sheehan JP: Effect of prior hemorrhage on intracranial arteriovenous malformation radiosurgery outcomes. Cerebrovasc Dis 39:53-62, 2015

22. Ding D, Yen CP, Starke RM, Xu Z, Sheehan JP: Radiosurgery for ruptured intracranial arteriovenous malformations. J Neurosurg 121:470-481, 2014

23. Ding D, Yen CP, Starke RM, Xu Z, Sun X, Sheehan JP: Outcomes following single-session radiosurgery for high-grade intracranial arteriovenous malformations. Br J Neurosurg 28:666-674, 2014

24. Ding D, Yen CP, Starke RM, Xu Z, Sun X, Sheehan JP: Radiosurgery for Spetzler-Martin Grade III arteriovenous malformations. J Neurosurg 120:959-969, 2014

25. Ding D, Yen CP, Xu Z, Starke RM, Sheehan JP: Radiosurgery for low-grade intracranial arteriovenous malformations. J Neurosurg 121:457-467, 2014

26. Ding D, Yen CP, Xu Z, Starke RM, Sheehan JP: Radiosurgery for patients with unruptured intracranial arteriovenous malformations. J Neurosurg 118:958-966, 2013

27. Ding D, Yen CP, Xu Z, Starke RM, Sheehan JP: Radiosurgery for primary motor and sensory cortex arteriovenous malformations: outcomes and the effect of eloquent location. Neurosurgery 73:816-824, 2013

28. Flickinger JC, Kondziolka D, Lunsford LD, Pollock BE, Yamamoto M, Gorman DA, et al: A multi-institutional analysis of complication outcomes after arteriovenous malformation radiosurgery. Int J Radiat Oncol Biol Phys 44:67-74, 1999

29. Flickinger JC, Kondziolka D, Pollock BE, Maitz AH, Lunsford LD: Complications from arteriovenous malformation radiosurgery: multivariate analysis and risk modeling. Int J Radiat Oncol Biol Phys 38:485-490, 1997

30. Fokas E, Henzel M, Wittig A, Grund S, Engenhart-Cabillic $\mathrm{R}$ : Stereotactic radiosurgery of cerebral arteriovenous malformations: long-term follow-up in 164 patients of a single institution. J Neurol 260:2156-2162, 2013

31. Friedman WA, Bova FJ: Radiosurgery for arteriovenous malformations. Neurol Res 33:803-819, 2011

32. Hong CS, Peterson EC, Ding D, Sur S, Hasan D, Dumont AS, et al: Intervention for A randomized trial of unruptured brain arteriovenous malformations (ARUBA) - Eligible patients: An evidence-based review. Clin Neurol Neurosurg 150:133-138, 2016

33. Izawa M, Chernov M, Hayashi M, Nakaya K, Kamikawa S, Kato K, et al: Management and prognosis of cysts developed on long-term follow-up after Gamma Knife radiosurgery for intracranial arteriovenous malformations. Surg Neurol 68:400-406, 2007

34. Izawa M, Hayashi M, Chernov M, Nakaya K, Ochiai T, Murata $\mathrm{N}$, et al: Long-term complications after gamma knife surgery for arteriovenous malformations. J Neurosurg 102 Suppl:34-37, 2005

35. Kano H, Lunsford LD, Flickinger JC, Yang HC, Flannery TJ, Awan NR, et al: Stereotactic radiosurgery for arteriove- 
nous malformations, Part 1: management of Spetzler-Martin Grade I and II arteriovenous malformations. J Neurosurg 116:11-20, 2012

36. Kim MS, Lee SI, Sim JH: A case of very large cyst formation with Gamma Knife radiosurgery for an arteriovenous malformation. Stereotact Funct Neurosurg 72 (Suppl 1):168-174, 1999

37. Lunsford LD, Kondziolka D, Flickinger JC, Bissonette DJ, Jungreis CA, Maitz AH, et al: Stereotactic radiosurgery for arteriovenous malformations of the brain. J Neurosurg 75:512-524, 1991

38. Maruyama K, Kawahara N, Shin M, Tago M, Kishimoto J, Kurita $\mathrm{H}$, et al: The risk of hemorrhage after radiosurgery for cerebral arteriovenous malformations. N Engl J Med 352:146-153, 2005

39. Maruyama K, Koga T, Shin M, Igaki H, Tago M, Saito N: Optimal timing for Gamma Knife surgery after hemorrhage from brain arteriovenous malformations. J Neurosurg 109 Suppl:73-76, 2008

40. Maruyama K, Shin M, Tago M, Kurita H, Kawahara N, Morita A, et al: Management and outcome of hemorrhage after Gamma Knife surgery for arteriovenous malformations of the brain. J Neurosurg 105 Suppl:52-57, 2006

41. Matsuo T, Kamada K, Izumo T, Hayashi N, Nagata I: Cyst formation after linac-based radiosurgery for arteriovenous malformation: examination of predictive factors using magnetic resonance imaging. Clin Neurol Neurosurg 121:10-16, 2014

42. Mouchtouris N, Jabbour PM, Starke RM, Hasan DM, Zanaty M, Theofanis T, et al: Biology of cerebral arteriovenous malformations with a focus on inflammation. J Cereb Blood Flow Metab 35:167-175, 2015

43. Oermann EK, Ding D, Yen CP, Starke RM, Bederson JB, Kondziolka D, et al: Effect of prior embolization on cerebral arteriovenous malformation radiosurgery outcomes: a casecontrol study. Neurosurgery 77:406-417, 2015

44. Oermann EK, Rubinsteyn A, Ding D, Mascitelli J, Starke $\mathrm{RM}$, Bederson JB, et al: Using a machine learning approach to predict outcomes after radiosurgery for cerebral arteriovenous malformations. Sci Rep 6:21161, 2016

45. Pan HC, Sheehan J, Stroila M, Steiner M, Steiner L: Late cyst formation following gamma knife surgery of arteriovenous malformations. J Neurosurg 102 Suppl:124-127, 2005

46. Pollock BE, Brown RD Jr: Management of cysts arising after radiosurgery to treat intracranial arteriovenous malformations. Neurosurgery 49:259-265, 2001

47. Przybylowski CJ, Ding D, Starke RM, Yen CP, Quigg M, Dodson B, et al: Seizure and anticonvulsant outcomes following stereotactic radiosurgery for intracranial arteriovenous malformations. J Neurosurg 122:1299-1305, 2015

48. Shuto T, Matsunaga S, Suenaga J: Surgical treatment for late complications following gamma knife surgery for arteriovenous malformations. Stereotact Funct Neurosurg 89:96102,2011

49. Shuto T, Ohtake M, Matsunaga S: Proposed mechanism for cyst formation and enlargement following Gamma Knife Surgery for arteriovenous malformations. J Neurosurg 117 Suppl:135-143, 2012

50. Shuto T, Yagishita S, Matsunaga S: Pathological characteristics of cyst formation following gamma knife surgery for arteriovenous malformation. Acta Neurochir (Wien) 157:293-298, 2015

51. Spetzler RF, Martin NA: A proposed grading system for arteriovenous malformations. J Neurosurg 65:476-483, 1986
52. Starke RM, Kano H, Ding D, Lee JY, Mathieu D, Whitesell $\mathrm{J}$, et al: Stereotactic radiosurgery for cerebral arteriovenous malformations: evaluation of long-term outcomes in a multicenter cohort. J Neurosurg 126:36-44, 2017

53. Starke RM, Yen CP, Ding D, Sheehan JP: A practical grading scale for predicting outcome after radiosurgery for arteriovenous malformations: analysis of 1012 treated patients. J Neurosurg 119:981-987, 2013

54. Steiner L, Lindquist C, Adler JR, Torner JC, Alves W, Steiner $\mathrm{M}$ : Clinical outcome of radiosurgery for cerebral arteriovenous malformations. J Neurosurg 77:1-8, 1992

55. Wegner RE, Oysul K, Pollock BE, Sirin S, Kondziolka D, Niranjan A, et al: A modified radiosurgery-based arteriovenous malformation grading scale and its correlation with outcomes. Int J Radiat Oncol Biol Phys 79:1147-1150, 2011

56. Yamamoto M, Hara M, Ide M, Ono Y, Jimbo M, Saito I: Radiation-related adverse effects observed on neuro-imaging several years after radiosurgery for cerebral arteriovenous malformations. Surg Neurol 49:385-398, 1998

57. Yang W, Porras JL, Garzon-Muvdi T, Xu R, Caplan JM, Hung AL, et al: Management outcome of brainstem arteriovenous malformations: the role of radiosurgery. World Neurosurg 94:64-72, 2016

58. Yang W, Porras JL, Hung AL, Khalid S, Garzon-Muvdi T, Caplan JM, et al: Risk of hemorrhage in patients over age 60 with arteriovenous malformations (AVMs). J Clin Neurosci 34:121-127, 2016

59. Yen CP, Ding D, Cheng CH, Starke RM, Shaffrey M, Sheehan J: Gamma Knife surgery for incidental cerebral arteriovenous malformations. J Neurosurg 121:1015-1021, 2014

60. Yen CP, Matsumoto JA, Wintermark M, Schwyzer L, Evans AJ, Jensen ME, et al: Radiation-induced imaging changes following Gamma Knife surgery for cerebral arteriovenous malformations. J Neurosurg 118:63-73, 2013

61. Yen CP, Sheehan JP, Schwyzer L, Schlesinger D: Hemorrhage risk of cerebral arteriovenous malformations before and during the latency period after Gamma Knife radiosurgery. Stroke 42:1691-1696, 2011

\section{Disclosures}

The authors report no conflict of interest concerning the materials or methods used in this study or the findings specified in this paper.

\section{Author Contributions}

Conception and design: Sheehan, Pomeraniec, Ding, Starke, Liu. Acquisition of data: all authors. Analysis and interpretation of data: all authors. Drafting the article: all authors. Critically revising the article: all authors. Reviewed submitted version of manuscript: all authors. Approved the final version of the manuscript on behalf of all authors: Sheehan. Statistical analysis: Sheehan, Pomeraniec, Ding, Starke, Liu. Administrative/technical/material support: all authors. Study supervision: Sheehan, Pomeraniec, Ding, Starke, Liu.

\section{Correspondence}

Jason Sheehan, Department of Neurological Surgery, University of Virginia, Box 800212, Charlottesville, VA 22908. email: jsheehan@virginia.edu. 